\title{
Comparison of L-Dopa content in three species of genus Mucuna by differente techniques
}

Ragni Vora ${ }^{1}$, Ambika N. Joshi ${ }^{1 *}$, Nitesh C. Joshi ${ }^{2}$

${ }^{1}$ Department of Botany, Jai Hind College, A road, Churchgate, Mumbai-400020, Maharashtra, India.

2Department of Botany, Rizvi College of Arts, Science and Commerce, Mumbai-400050, Maharashtra India.

Received: 22-12-2017; Accepted: 30-12-2017

\begin{abstract}
In the present study, attempts are made to develop suitable method(s) for extraction of L-DOPA from the powdered seeds of 3 species of Mucuna using different solvents and conditions. The seed powder of both plants was subjected to 6 different extraction methods, with different solvent ratios. All the extracts were analyzed using RPHPLC and were validated according to The International Conference on Harmonisation of Technical Requirements for Registration of Pharmaceuticals for Human Use guidelines. The L-DOPA extraction was best with Methanol Water mixture in a cold maceration technique and overall gives good extraction efficiency in all the three plants giving concentrations of $5.03 \%, 13.36 \%$ and $16.78 \%$ of L-DOPA in Mucuna gigantea, Mucuna pruriens and Mucuna monosperma, respectively. The present investigation was done to study the extraction efficiency of various extraction methods of LDOPA content in seed extracts of Mucuna and compare it.
\end{abstract}

Keywords: Comparison, Extraction efficiency, HPLC, Intra-specific, L-DOPA, Mucuna

\section{Introduction}

L-(3,4-dihydroxyphenyl)-L-alanine(L-DOPA) is a precursor to many neurotransmitters like dopamine, norepinephrine (noradrenaline), and epinephrine. LDOPA crosses the Brain Blood Barrier whereas, dopamine cannot. In the Central Nervous System, L-DOPA converted into dopamine by the enzyme aromatic L-amino acid decarboxylase, also known as DOPA decarboxylase (DDC) (Simuni and Hurtig, 2008).

Various Mucuna species have been studied in developing countries as cover crops for food selfsufficiency development and soil fertility improvement; furthermore, their bioactive substances have been thoroughly evaluated, particularly L-DOPA (Tse et.al., 2013). In contemporary medicine, Mucuna remains a genus of interest since its L-DOPA content and use in the treatment of Parkinson's disease continues to be evaluated in biochemical research (Manyam et. al., 2004).

Mucuna pruriens is commonly known as velvet bean, cowitch, cowhage, etc. M. pruriens has long been used in traditional Ayurvedic Indian medicine for many diseases (Katzenschlager et. al., 2004). The seeds are noted to be a natural source of L-DOPA and are also used as a substitute for the synthetic LDOPA (Ramya and Thaakur, 2007). It is also known to show wonders as antiparkinson's, aphrodisiac, antidiabetic, male infertility and neuroprotective activities (Vaidya et. al., 1978; Sharma et. al., 2000; Katzenschlager et. al., 2004).

\footnotetext{
*Corresponding Author:

Prof. Ambika N. Joshi,

Department of Botany, Jai Hind College,

A road, Churchgate, Mumbai-400020,

Maharashtra, India.

E-mail: ambikapurijoshi@gmail.com
}

Mucuna monosperma is commonly known as Negrobean \& periyattalargai (Poornachandra et. al., 2005). Its seed materials have lately received more attention. Crude proteins, crude lipids, ash and nitrogen free extractives constituted $30.62 \%, 9.03 \%$, $5.99 \%$ and $42.79 \%$, respectively have been reported in the seeds. The seeds are also rich in minerals like potassium, calcium, magnesium and iron (Pugalenthi et. al., 2003). Anti-nutritional substances like total free phenols, tannins, and L-DOPA were also investigated (Arulmozhi and Janardhanan, 1992).

Mucuna gigantea, also known commonly as Seabean, or in Hawaiian as Kāece, is indigenous to the Hawaiian Islands. Their pods show a range of color from green to brown and has hair-like structure called trichomes on it (Tse et. al., 2013). These seeds have high amounts of crude protein, crude fat, total free phenols and tannins when compared to other legumes. Researchers have shown that the amount of L-DOPA could be reduced to a great extent just by cracking and rinsing the seeds under running water, proving that L-DOPA is very much present in the seeds (Tse et. al., 2013)

\section{Materials and Methods}

Collection and preparation of Sample: M. gigantea seeds were received from The Botanic Reserves of the Cairns Regional Council, Australia. M. prureins pods were collected from Sanjay Gandhi National Park, Borivali; Mumbai, India on February 2015 and M. monosperma pods were collected from the forest 
area of Ganeshgudi, Dandeli; Karnataka, India. The pods were dry roasted so as the burn the external itchy trichomes and it also facilitated in opening the pods with ease. The seeds were collected and were kept in a hot air oven at $40^{\circ} \mathrm{C}$ for checking its water loss. The Dried seeds were powdered using a grinder and passed through a sieve to achieve fine powder.

\section{Preparation of Standard}

99.9\% pure L-DOPA standard was obtained from Pallav Chemicals and 1000 ppm standard stock was prepared (Rathod and Patel, 2014).

\section{Chromatographic conditions instrumentation}

Chromatographic separation was performed with AGILENT HPLC (Model no. 1220 Infinity) equipped with binary pump and auto-injector

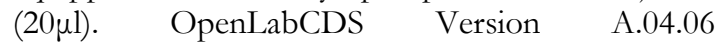
chromatographic software was used for data acquisition. Kromasil100-5-C18 (250mm $\times 4.6 \mathrm{~mm}$ $\times \quad 5 \mu)$; Part / Serial No: M05CLA25/E117509column was used for analysis. Mobile Phase used was water / Methanol / AcetoNitrile (100:60:40) (v/v) containing 0.2\% Triethylamine, $\mathrm{pH}=3.3$ was filtered through 0.45 micron membrane filter (Millipore) and degassed by sonication; flow rate of $1 \mathrm{ml} / \mathrm{min}$ was maintained throughout the run. The column effluent was monitored at $280 \mathrm{~nm}$ with variable wavelength UV detector (Rathod and Patel, 2014).

\section{Method Validation}

Validation of the HPLC method was carried out as per ICH guidelines (ICH Guidelines). Parameters such as Linearity, Accuracy, Precision, LOD and LOQ were taken up as tests for analytical method validation and the values are listed in table 1.

\section{Preparation of the Plant Extracts}

Extracts were made using various techniques as listed below:

Method 1 (Takashi et. al., 2011):

This method was proposed by Takashi et. al., 2011. The preparation of the sample remained the same and only the solvents used for the extraction have been changed so as to check the extraction efficiency of the same procedure with different concentration. The various solvent systems used were:

Method 1.1: acetonitrile:water:formic acid (80:20:1)

Method 1.2: acetonitrile:water (50:50),

Method 1.3: acetonitrile:water:formic acid (50:50:1),

Method 1.4: acetonitrile:formic acid (100:1),

Method 1.5: acetonitrile: water (80:20)

Method 2 (Misra and Wagner, 2014):

1. The seed powder was defatted with acetone and then suspended in water: ethanol (1:1) with 0.1 \%ascorbic acid for 3 overnights. This was performed with regular change of solvents.

2. It was diluted $1: 100$ by using water: ethanol $(1: 1)$ with $0.1 \%$ ascorbic acid for HPLC analysis.

Method 4 (Vachhani et. al., 2011):

1. The seed powder was suspended in Water: Methanol (50:50) (v/v) and let it stand for $2 \mathrm{hrs}$ unlike the original method.

Method 5 (Raina and Khatri, 2011):

1. In this method, heat reflux was done for the seed powder using $0.1 \mathrm{~N} \mathrm{HCl}$ solution.

d Method 6 (Kasture et. al., 2014):

1. The seed powder was treated with water: ethanol 30:70, kept in tightly closed container for 7 days.

2. The supernatant was separated.

\section{Results and Discussions}

The HPLC method discussed in the present work provides a convenient and accurate way for analysis of L-DOPA in three species of Mucuna. The retention time of standard L-DOPA is 2.363 mins as shown in Fig. 1. As shown in Fig. 2, 3 and 4, respectively, $M$. pruriens extract shows retention time of 2.333 mins, $M$. monosperma extract shows retention time at $2.350 \mathrm{mins}$ and $M$. gigantea extract shows retention time 2.327 mins. The match in the retention time confirms the presence of L-DOPA in all three-selected species of Mucuna. For quantitation purposes all the plant extract was made in triplicates and tested by HPLC. The Area under the Curve/ peak area was considered and used for calculations. The Formulae used were as follows (HPLC training, Chromacademy):

$$
\text { Response factor }=\frac{\text { Peak Area }}{\text { Standard Amount }}
$$

Amount of Unknown in the sample $=\frac{\text { Peak Area }}{\text { Response Factor }}$

$$
\% \text { Content }=\frac{C \times V \times D}{10000 \times W}
$$

Where,

$\mathrm{C}=$ conc in $\mathrm{mg} / \mathrm{L}$

$\mathrm{D}=$ dilution factor

$\mathrm{V}=$ final total volume

$\mathrm{W}=$ Weight of the sample taken in $\mathrm{g}$

Table 1. Method validation parameters

\begin{tabular}{lc}
\hline \multicolumn{1}{c}{ Parameters } & Values \\
\hline Linearity & $100-700 \mathrm{ppm}$ \\
Correlation coefficient & 0.992 \\
Accuracy & $98.83 \%$ recovery \\
(Standard Addition Method) & \\
Presicion & \\
Intraday & 0.189 \\
Interday & 0.754 \\
Limitof Detection(LOD) & $2 \mathrm{ppm}$ \\
Limit of Quantitation (LOQ) & $5 \mathrm{ppm}$ \\
Stability & Assay not decreased below $8 \%$ \\
\hline
\end{tabular}


Table 2. Mean Values of percent concentration of L-DOPA in the three-selected species of Genus Mucuna

\begin{tabular}{|c|c|c|c|}
\hline Method & M. prureins (\%) & M. monosprema (\%) & M. gigantean (\%) \\
\hline 1.1 & 2.257 & 1.74 & 0.726 \\
\hline 1.2 & 4.157 & 4.088 & 2.936 \\
\hline 1.3 & 4.806 & 6.545 & 3.864 \\
\hline 1.4 & 0.958 & 1.234 & 0.79 \\
\hline 1.5 & 0.843 & 0.78 & 0.466 \\
\hline 2 & 8.81 & 9.333 & 4.334 \\
\hline 4 & 13.362 & 16.78 & 5.038 \\
\hline 5 & 8.722 & 9.084 & 4.564 \\
\hline 6 & 2.134 & 2.337 & 1.772 \\
\hline
\end{tabular}

Figure 1. Chromatogram of the Standard

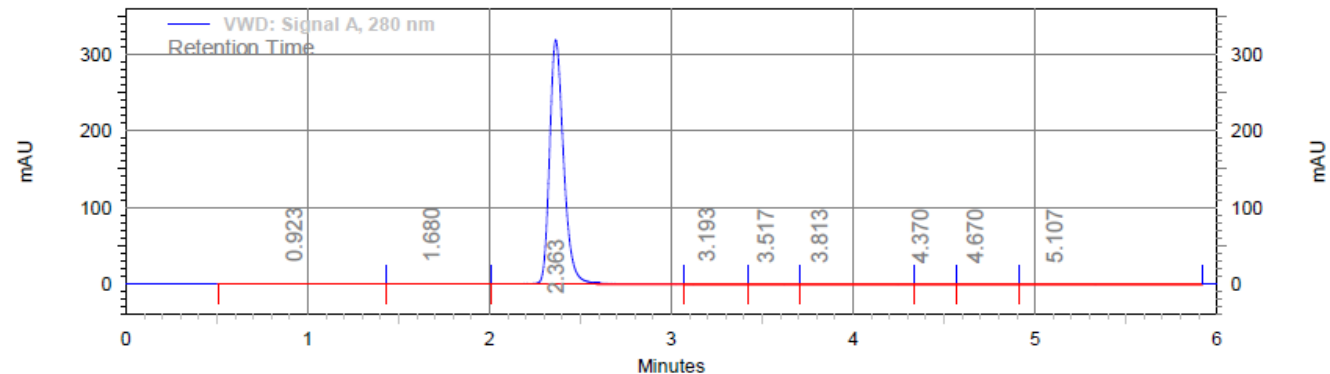

Figure 2. Chromatogram of Method 4 for $M$. prureins

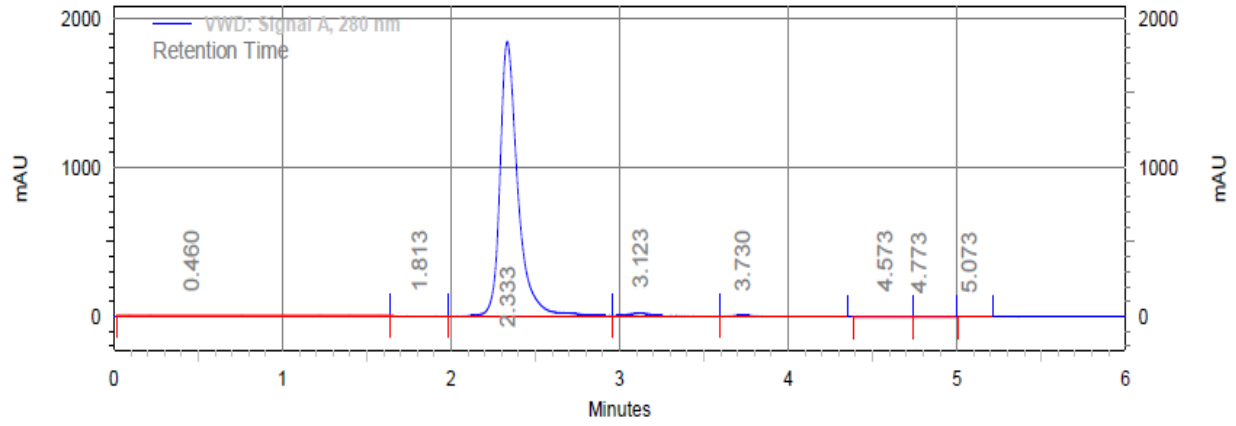

Figure 3. Chromatogram of Method 4 for M. monosperma

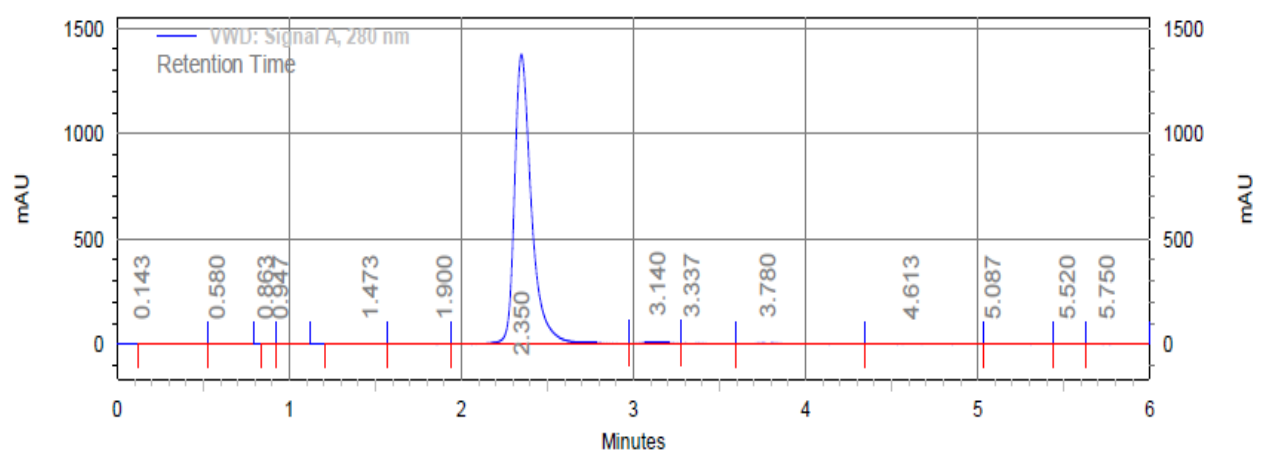

Figure 4. Chromatogram of Method 4 for M. gigantea

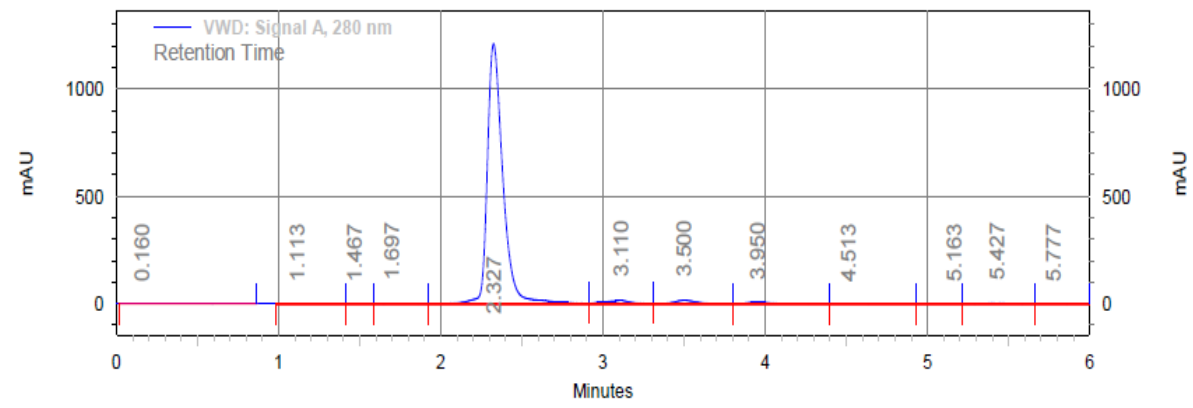


Figure 5. Comparison of extraction efficiency of L-DOPA from all three-selected species of Genus Mucuna

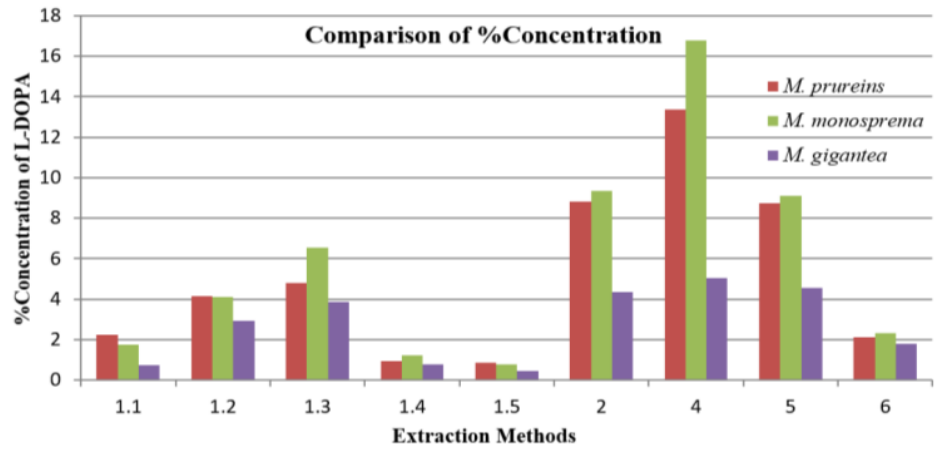

In the proposed method, Linearity was observed in the concentration range of $100-700 \mathrm{ppm}$. The mean values of L-DOPA content in the seed powder extracted by each of these methods are compiled in Table 2 and Figure 5.

$M$. gigantea showed the relatively low concentration of L-DOPA in comparison with other two plants for all the methods. Method 2 and Method 4 were good methods regarding its extraction efficiency where all the three plants show approximately, $4 \%$, $8 \%$ and $9 \%$ L-DOPA in M. gigantea, M. pruriens and M. monosperma, respectively. The L-DOPA extraction was best by Method 4 i.e. with Methanol Water mixture in a cold maceration technique and overall gives good extraction efficiency in all the three plants giving concentrations of $5.03 \%, 13.36$ $\%$ and $16.78 \%$ of L-DOPA in $M$. gigantea, $M$. pruriens and $M$. monosperma, respectively. Method 1.4 and 1.5 showed the least concentration of L-DOPA in all the three-selected species.

\section{Conclusion}

Use of suitable extraction methods will increase versatile utilization of these seeds with high levels of bioactive compounds for the management of chronic diseases like Parkinson's. The present investigation suggests Water-Methanol system to remain the best solvent from all the solvents used for maximum extraction of L-DOPA for all the three species. According to literature much work is done on $M$. prureins and its L-DOPA content; through this present study we can conclude $M$. monosperma to be a better source of L-DOPA. This will further help standardize procedures for extraction of L-DOPA from Mucuna plants and make a natural medicine against the symptoms of various diseases. However, for industrial application purposes, further investigations are required to develop a mathematical model to control and predict the optimization parameters of the extraction process.

\section{Acknowledgements}

The authors would like to display sincere gratitude to Dr. J. S. Wagh, General Manager, Services,
Waters India Pvt. Ltd. to lend us the HPLC column. Also, the authors would like to acknowledge the teaching and non-teaching staff of Botany department at Jai Hind College, Mumbai, for their constant help and guidance.

\section{References}

1. Arulmozhi, M., and K. Janardhanan. "The Biochemical Composition and Nutritional Potential of The Tribal Pulse, Mucuna monosperma DC ex Wightii." Plant Food for Human Nutrition 42.1 (1992): 45-53.

2. http://www.chromacademy.com/hplc-training.html

3. https://www.ich.org/fileadmin/Public_Web_Site/IC H_Products/Guidelines/Quality/Q2_R1/Step4/Q2 _R1_Guideline.pdf

4. Kasture, Veena, Vijay Sonar, Poonam Patil, and Deepak Musmade. "Quantitative Estimation of LDOPA from Polyhebal Formulation by using RPHPLC." American Journal of Pharmtech Research 4.3 (2014): 408-414.

5. Katzenschlager, R, A. Evans, A Manson, P.N. Patsalos, N. Ratnaraj, H. Watt, L. Timmermann,R. Van der Giessen, and A.J. Lees. "Mucuna pruriens In Parkinson's Disease: A Double Blindclinical and Pharmacological Study." Journal of Neurology, Neurosurgery, and Psychiatry 75.12 (2004): 1672-1677.

6. Manyam, B.V., M. Dhansekaran, and T.A. Hare. "Neuroprotective Effects of the Antiparkinson Drug Mucuna pruriens." Phytotherapy Research 18 (2004): 706.

7. Misra, L, and H. Wagner. "Extraction of Bioactive Principles from Mucuna Pruriens Seeds." Indian Journal of Biochemistry and Biophysics 44 (2014): 56-60.

8. Poornachandra, M.N., S. Khanum, B.G. Shivanada, T.N. Shivanada, and R. Dris. "Mucuna pruriens (L) DC - A Novel Drug for Learning and Memory Retrieval." Journal of Food, Agriculture and Environment 3 (2005): 13.

9. Pugalenthi, M, V. Vadivel, P. Gurumoorthi and K. Janardhanan. "Nutritional Potential of an UnderExploited Legume, Mucuna monosperma DC ex Wight." Indian Journal of Agricultural Biochemistry 16 (2003): 73 78 
10. Raina, A.P., and R. Khatri. "Quantitative Determination of L-DOPA in Seeds of Mucuna pruriens Germplasm by High Performance Thin Layer Chromatography." Indian Journal of Pharmaceutical Sciences 73.4 (2011) L: 459-462.

11. Ramya, K.B., and S. Thaakur. "Herbs Containing LDOPA: An Update." Ancient Science of Life 27.1 (2007) $50-55$.

12. Rathod, B.G., and N.M. Patel. "Development of Validated Rp-Hplc Method for The Estimation of LDOPA from Mucuna pruriens, Its Extracts and In Aphrodisiac Formulation." International Journal of Pharmaceutical Science and Research 5 (2014): 508-513.

13. Sharma P.C., M.B. Yelne, and T.J. Dennis. "Data Base on Medicinal Plants Used in Ayurveda." Central Council for Research in Ayurveda and Siddha 1 (2000): 200-203.

14. Simuni T., and H. Hurtig. "Levodopa: Pharmacologic Miracle Four Decades Later. In: Factor SA, Parkinson's Disease-Diagnosis and Clinical Management". Weiner WJ (eds). Demos, New York, (2008): 471-490.

15. Takashi H., I. Takahashi, K. SaijoMasaaki, F. Tomohide, N. Tomoko, M. Yuji. "Quantitative Determination of L-DOPA in Dietary Supplements
Containing Mucuna pruriens by High Performance Liquid Chromatography" Chiba Prefecture Wei Yan Annual Report 60 (2011): 53-56.

16. Tse G.G., B.B. Kim, A.M. McMurtray, and B.K. Nakamoto. "Case of Levodopa Toxicity from Ingestion of Mucuna gigantean." Hawaii Journal of Medicine and Public Health 72.5 (2013): 157-160.

17. Vachhani U.D., M. Trivedi, A. Bajaj, C.P. Shah. "A HPTLC Method for Quantitative Estimation of LDOPA from Mucuna pruriens in Polyherbal Aphrodisiac Formulation." Research Journal of Pharmaceutical, Biological and Chemical Sciences 2.2 (2011): 389.

18. Vaidya A.B., T.G. Rajagopalan, N.A. Mankodi, D.S. Antarkar, P.S. Tathed, A.V. Purohit and N.H. Wadia. "Treatment of Parkinson's Disease with the Cowhage Plant-Mucuna pruriens Bak." Neurology India 26.4 (1978): 171-6.

\section{Cite this article as:}

Ragni Vora, Ambika N. Joshi, Nitesh C. Joshi. Comparison of L-Dopa content in three species of genus Mucuna by differente techniques. Annals of Plant Sciences 7.1 (2018) pp. 1973-1977.

do http://dx.doi.org/10.21746/aps.2018.7.1.10

Source of support: Director, Botanical Survey of India Conflict of interest: Nil 